\title{
Sustainable production of drug-loaded particles by membrane emulsification
}

\author{
Airama Albisa, Emma Piacentini, Manuel Arruebo, Victor Sebastian Cabeza, and Lidietta Giorno
}

ACS Sustainable Chem. Eng., Just Accepted Manuscript • DOI: 10.1021/

acssuschemeng.8b00401 - Publication Date (Web): 13 Mar 2018

Downloaded from http://pubs.acs.org on March 13, 2018

\section{Just Accepted}

\begin{abstract}
"Just Accepted" manuscripts have been peer-reviewed and accepted for publication. They are posted online prior to technical editing, formatting for publication and author proofing. The American Chemical Society provides "Just Accepted" as a service to the research community to expedite the dissemination of scientific material as soon as possible after acceptance. "Just Accepted" manuscripts appear in full in PDF format accompanied by an HTML abstract. "Just Accepted" manuscripts have been fully peer reviewed, but should not be considered the official version of record. They are citable by the Digital Object Identifier (DOI®). "Just Accepted" is an optional service offered to authors. Therefore, the "Just Accepted" Web site may not include all articles that will be published in the journal. After a manuscript is technically edited and formatted, it will be removed from the "Just Accepted" Web site and published as an ASAP article. Note that technical editing may introduce minor changes to the manuscript text and/or graphics which could affect content, and all legal disclaimers and ethical guidelines that apply to the journal pertain. ACS cannot be held responsible for errors or consequences arising from the use of information contained in these "Just Accepted" manuscripts.
\end{abstract}




\title{
Sustainable production of drug-loaded particles by membrane emulsification
}

\author{
Airama Albisa ${ }^{1,2,3}$, Emma Piacentini $^{3^{*}}$, Manuel Arruebo $^{1,4}$, Victor Sebastian $^{1,4^{*}}$, Lidietta Giorno ${ }^{3}$ \\ ${ }^{1}$ Department of Chemical \& Environmental Engineering \& Nanoscience Institute of Aragon (INA), \\ University of Zaragoza, Mariano Esquillor edif. I+D, 50018 Zaragoza, Spain. \\ ${ }^{2}$ Department of Environmental and Chemical Engineering, University of Calabria (DIATIC-UNICAL), \\ via P. Bucci Cubo 45a, 87036 Rende (CS), Italy \\ ${ }^{3}$ Institute on Membrane Technology, National Research Council, ITM-CNR, Via P. Bucci 17/C, \\ 87036 Rende (CS), Italy \\ ${ }^{4}$ CIBER de Bioingeniería, Biomateriales y Nanomedicina (CIBER-BBN), Centro de Investigación \\ Biomédica en Red, C/Monforte de Lemos 3-5, Pabellón 11, 28029 Madrid, Spain \\ * Corresponding Authors \\ Emma Piacentini: e.piacentini@itm.cnr.it \\ Víctor Sebastián: victorse@unizar.es
}




\begin{abstract}
As the field of drug delivery is expanding into consumer products, it is essential to advance in the development of efficient synthesis technologies while preserving, at the same time, human health and the environment for future generations. Here, the sustainable development of polymeric particles for drug delivery is described. Poly(ethylene glycol) methyl ether-block-poly(lactide-coglycolide) based particles containing dexamethasone were produced by membrane emulsificationsolvent diffusion methods. The ability of the synthesis process to control particle-size distribution and morphology and its green impactful (energy consumption, simple (sEF) and complete (cEF) E factor) were evaluated.

Particles with sufficiently narrow distribution in their droplet size and mean diameter similar to the membrane pore diameter were produced by increasing the dispersed phase flux to $12.84 \mathrm{~L} \mathrm{~h}^{-}$ ${ }^{1} \mathrm{~m}^{-2}$, minimizing the maximum shear stress to $1.12 \mathrm{~Pa}$ and the energy consumption to $3.9610^{5} \mathrm{Jm}^{-}$ 3. The impact of the solvent used on size distribution, particles morphology and green performance scores was also studied. More uniform particles, with dense and slightly rough surface, high encapsulation efficiency and drug loading were obtained by replacing Dichloromethane with Ethyl acetate. The E factor was also decreased by $80 \%$.

Results demonstrated that membrane emulsification is an environmentally improved method for the production of drug delivery systems with enormous impact in terms of formulation quality, energy consumption reduction and waste minimization.
\end{abstract}

Keywords: membrane emulsification, drug-loaded particles, energy consumption, sustainability, PLGA-PEG, Ethyl acetate, dexamethasone 


\section{Introduction}

Among the new generation of pharmaceutical forms, polymeric particles have gained significant relevance due to their ability to deliver drugs at a controlled rate and toward a specific $\operatorname{target}^{1}$. Polymeric particles have been frequently used as drug delivery depots of drugs with low aqueous solubility. Approximately $40 \%$ of all new drug candidates in development, and about $70-80 \%$ in some therapeutic areas, are poorly absorbed orally, principally due to their low aqueous solubility. As the field of drug delivery is expanding into consumer products, it is essential to advance in the development of efficient synthesis technologies while preserving, at the same time, human health and the environment for future generations. The design of highly efficient particulate systems with high yield, minimizing solvent and energy consumption and with a reduced waste production is a significant challenge in particle engineering technologies. ${ }^{2-4}$ Producers are making a big effort to create the basis to regulate process manufacturing procedures to reach high quality products, with high productivity and to fulfill also the requirements of the pharmacopeia ${ }^{5,6}$.

Biodegradability or biocompatibility is an essential requirement for the polymer used for pharmaceutical applications ${ }^{7}$. Several drug delivery systems based on poly (D,L-lactide-coglycolide) (PLGA) family are approved by the FDA and their ability to modulate drug release are strictly connected with the relative amount of lactic (PLA) and glycolic acids (PGA) ${ }^{8,9}$. The modification of PLGA with an hydrophilic and inert polymer like PEG (poly ethylene glycol) prolongs the circulation of the particles in the body and decreases the premature drug release increasing their therapeutic effect ${ }^{10}$. Dexamethasone (DEX) is currently used in many biomedical applications such as: cell culture, ophthalmology, proliferative vitreoretinopathy, subretinal neovascularization, arthritis and diabetic macular edema as anti-inflammatory and immunosuppressant drug ${ }^{11}$. The main limitations of this drug for pharmaceutical applications are its high hydrophobicity and high doses necessary to reach its therapeutic level ${ }^{11,12}$. Consequently, 
various delivery systems have been developed and the majority of them are based on its encapsulation within both natural and synthetic polymers ${ }^{11,13-15}$.

Microencapsulation by solvent evaporation is a widely applied technique for entrapping insoluble or poorly water-soluble drugs. Different aspects have to be taken into account to choose the most appropriate solvent for the preparation of polymeric particles by this technique: 1) the ability to dissolve the polymer 2) a reduced solubility in the continuous phase 3) high volatility 4) low toxicity ${ }^{7}$. Solvents used during polymer particle synthesis are often volatile organic compounds and their use is associated to some concerns about their potential environmental impact (some of them are able to form low-level ozone and smog through free radical air oxidation processes), their adverse health effects (ranging from carcinogenic properties to headaches and allergic skin reactions, eye irritations) and their hazardous properties (they are often highly flammable) ${ }^{16}$. Dichloromethane (DMC) is one of the most used solvents for the production of polymeric particles via emulsification and subsequent solvent-evaporation due to its high volatility, low boiling point and high immiscibility with water ${ }^{7}$. Ethyl acetate (EA) has been proven to be a potential substitute of DCM with less toxicity ${ }^{7,17-20}$. It has been classified as "recommended" considering the safety, health and environmental scores while DCM is considered "problematic" or "hazardous" 21,22.

Microengineered technologies are emerging as promising particle fabrication methods for their ability to generate droplets individually by injecting the dispersed phase in the continuous phase through a single (i.e., microfluidic device) or a multitude of channel/pores (i.e., membranes) ${ }^{23,24}$. These techniques allow the production of uniformly sized droplets with tuned sizes and improved encapsulation efficiency ${ }^{25-28}$. Polymeric particles can be obtained by combining membrane emulsification with additional physical (i.e., evaporation/solvent diffusion) or chemical (crosslinking, coacervation and interfacial polymerization) treatments. This allows controlling the 


\section{Materials and Method}

\section{$\underline{\text { Materials }}$}

The polymer used in this study was Resomer RGP d 5055 (Di-block PLGA (50:50) PEG (5kDa, 5\%) (PLGA-PEG), EVONIK, Germany). Dexamethasone (DEX) supplied by SIGMA-Aldrich was used as model drug. Pluronic F127 was used as stabilizer in the external phase during the 
microencapsulation process and Ethyl acetate (EA) and Dichloromethane (DCM) were used as nonpolar solvents. Surfactants and solvents (analytical grade) were purchased from SIGMA-Aldrich.

\section{Dispersed Phase and continuous phase preparation}

The dispersed phase used to produce the o/w emulsion was obtained by dissolving PLGA-PEG in EA at a polymer concentration of $10 \mathrm{mg} \mathrm{mL}^{-1}$. The continuous phase was a water solution containing Pluronic F127 at $11.6 \mathrm{mg} \mathrm{mL}^{-1}$. A continuous phase saturated in Ethyl Acetate was used during the emulsification step in order to avoid its diffusion from the formed droplets while a nonsaturated continuous phase was used as dilution medium for the preparation of the particles by solvent diffusion, after emulsification.

To evaluate the dexamethasone encapsulation efficiency and drug loading, the dispersed phase was modified by including dexamethasone $\left(1 \mathrm{mg} \mathrm{mL}^{-1}\right)$.

\section{Membrane emulsification step}

The o/w emulsion was prepared by using a Shirasu porous glass-based (SPG, Miyazaki, Japan), hydrophilic tubular membrane with a pore size of $1 \mu \mathrm{m}$ having a membrane area of $31.30 \mathrm{~cm}^{2} . \mathrm{A}$ schematic representation of the membrane and the membrane emulsification plant are reported in Figure 1. The dispersed phase was injected through the membrane under gas pressure using a transmembrane pressure $\left(\mathrm{P}_{\mathrm{TM}}\right)$ between 0.18 and $0.45 \mathrm{~Pa}$, corresponding to a dispersed flux $\left(\mathrm{J}_{\mathrm{d}}\right)$ between 1.16 and $30.67 \mathrm{Lh}^{-1} \mathrm{~m}^{-2}$. The dispersed phase flux $\left(J_{d}\right)$ was determined as follows:

Equation 1: $J_{d}=\frac{Q_{d}}{A}$

Where, $Q_{d}$ is the Dispersed Phase Flow $\left(L \cdot h^{-1}\right)$ and $A$ is the Membrane Area $\left(\mathrm{m}^{2}\right)$. It represents a measurement of membrane emulsification throughput. 


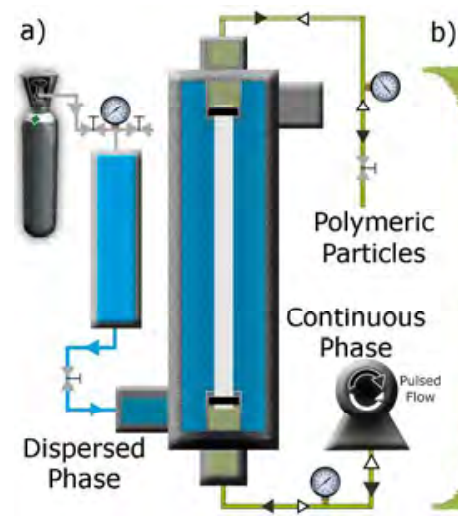

b) Green Process Enginering: Membrane emulsification

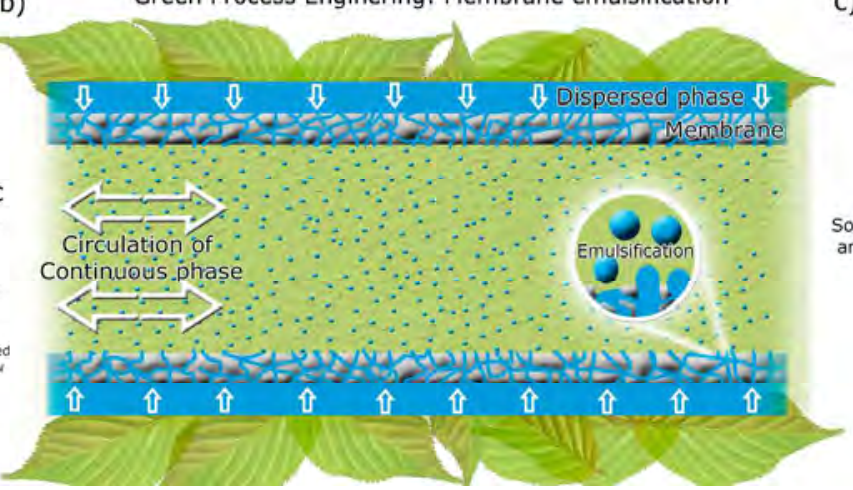

c)

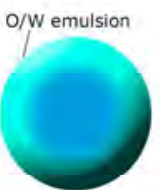

Solvent diffusion and evaporation

Figure 1. A) Schematic representation of the membrane emulsification set up. B) Schematic representation of membrane emulsification process. C) Schematic representation of solvent diffusion - evaporation process.

The continuous phase was agitated by means of a pulsed back-and-forward mode along the lumen side of the membrane by using a programmable peristaltic pump (Digi-Staltic double-Y Masterflex ${ }^{\circledast}$ pump Micropump, model GJ-N23.JF1SAB1). ${ }^{32,33}$ The maximum shear stress ( $\left.\tau_{\max }\right)[\mathrm{Pa}]$ at the membrane surface depends on the frequency (f) $[\mathrm{Hz}]$ and on the amplitude $(\alpha)[\mathrm{m}]$ of the continuous phase flow. The amplitude and the frequency of the oscillation were calculated considering the flow rate of the pump (Qc) $\left[\mathrm{m}^{3} \cdot \mathrm{s}^{-1}\right]$ and the volume of the continuous phase that was pumped inside the membrane before the flow direction was reversed (Vc) [L]. These parameters were calculated as follows:

$$
\begin{aligned}
& \text { Equation 2: } \tau_{\max }=2 \alpha(\pi f)^{1.5}\left(\mu_{c} \rho_{c}\right)^{0.5} \\
& \text { Equation 3: } \alpha=\frac{4 V c}{\pi d_{h}^{2}} \\
& \text { Equation 4: } f=\frac{2 Q c}{V c}
\end{aligned}
$$


Where $\mu_{\mathrm{c}}$ is the Continuous phase viscosity $[\mathrm{Pa} \cdot \mathrm{s}]$ and $\rho_{\mathrm{c}}$ is the Continuous phase density $\left[\mathrm{kg} \cdot \mathrm{m}^{-3}\right]$. The effect of amplitude was fixed at $4.7 \cdot 10^{-2} \mathrm{~m}$ and frequency was modified between 1.48 and 3.57 $\mathrm{Hz}$.

The volume ratio \% of the dispersed phase obtained for each experiment respect to the continuous phase volume (DP/CP) was $20 \%$. The emulsification process was carried out at $20 \pm 5^{\circ} \mathrm{C}$. The membrane was pre-wetted in the continuous phase solution before each experiment. After each experiment, a membrane cleaning step was carried out by using acetone and EA ${ }^{34}$.

The water permeability of a brand new membrane before each experiment was measured to evaluate its recovery after the cleaning procedure and it was set at $7523.00 \pm 80.00 \mathrm{Lh}^{-1} \mathrm{~m}^{-2} \mathrm{bar}^{-1}$.

\section{$\underline{\text { Solidification Step }}$}

The liquid droplets were precipitated as solid microparticles by the addition of a certain volume of non-saturated continuous phase (diffusion volume, $V_{d}$ ). The diffusion volume was selected taking into account the theoretical minimum volume $\left(\mathrm{V}_{\mathrm{th}}\right)$ (i.e., the minimum theoretical amount of diffusion volume necessary to ensure the complete diffusion of solvent), calculated using equation 1. The $V_{d} / V_{h}$ ratio was changed from 0 to 3 in order to control the solidification rate of the droplets. $V_{d} / V_{t h}=0$ corresponded to the case in which the solidification was carried out without the addition of the non-saturated continuous phase.

Equation 5: $\quad V_{t h}=\frac{V_{D P}+\mathrm{S}_{\text {solvent }} * V_{C P}}{\mathrm{~S}_{\text {solvent }}}$

Where $V_{t h}(m L)$ is the theoretical minimum volume of the organic solvent, $V_{D P}(m L)$ is the dispersed phase volume, $\mathrm{S}_{\text {solvent }}\left(\mathrm{mL}\right.$ solvent/mL water) is the solubility of the organic solvent in water and $\mathrm{V}_{\mathrm{CP}}$ $(\mathrm{mL})$ is the continuous phase volume. 
The organic solvent was removed by evaporation in a fume hood under stirring for 3 hours. The resulting particles were centrifuged at $2100 \mathrm{~g}$ for $10 \mathrm{~min}$ and the supernatant was stored for further analysis while the pellet was lyophilized using a LyoAlfa 10/15 from Telstar for $24 \mathrm{~h}$ (0.01 bar, $\left.-40^{\circ} \mathrm{C}\right)$.

\section{$\underline{\text { Particles characterization }}$}

\section{Particle analysis}

The particle size analysis of the resulting microparticles was performed by using laser diffraction in a Malvern Mastersizer 2000 (Malvern Instruments, Worcestershire, UK). The software used to collect and analyze the data was a Malvern 2000 Software 5.61 using a refractive index of 1.55 PLGA-PEG polymer.

Microparticles were also observed by Scanning Electron Microscopy (SEM) using an Inspect F50 SEM operated at 10-15 kV; FEI from Eindhoven, Netherlands at the LMA-INA-Universidad de Zaragoza facilities. To perform the measurement, the sample was stained with a phosphotungstic acid solution $\left(75 \mathrm{mg} \mathrm{mL}^{-1}\right)$ and washed three times with distilled water. One drop of the particulate dispersion was placed on a glass slide, dried overnight and cover with platinum before observation. The size distribution was expressed in terms of the surface weighed median diameter or Sauter diameter $(D(3,2))$ calculated according to Equation 2. Volume weighed median diameter or Brouckere diameter $(D(4,3))$ was calculated according Equation 3.

Equation 6: $D(3,2)=\frac{\sum D_{i}^{3} n_{i}}{\sum D_{i}^{2} n_{i}}$

Equation 7: $D(4,3)=\frac{\sum D_{i}^{4} n_{i}}{\sum D_{i}^{3} n_{i}}$

Where $D_{i}$ is particle diameter of class $i$ and ni is number of particles in class $i$. 
The width of particle size distribution was expressed as Span number calculated by Equation 4

Equation 8: Span $=\frac{\mathrm{D}(90)-\mathrm{D}(10)}{\mathrm{D}(50)}$

Where $D(X)$ is the diameter corresponding to the percent of volume on a relative cumulative particle size curve.

\section{Encapsulation Efficiency and Drug Loading}

The encapsulation efficiency $(E E)$ and drug loading $(D L)$ were evaluated according to the following equations (Equation 5 and Equation 6):

Equation 9: $\mathrm{EE}=\frac{\text { DEX encap }}{\text { DEX total }} * 100$

Equation 10: DL $=\frac{\text { DEX encap }}{\text { PLGA total }} * 100$

Where EE is the encapsulation efficiency (\%), DEX encap stands for Dexamethasone mass encapsulated $(\mathrm{mg})$ measured by mass balance, $\mathrm{DEX} \mathrm{X}_{\text {total }}$ stands for the initial Dexamethasone mass in the dispersed phase $(\mathrm{mg})$, DL represents the drug loading efficiency (\%) and PLGA total stands for the initial PLGA mass in the dispersed phase $(\mathrm{mg})$. The particles were separated from the liquid by centrifugation at $2100 \mathrm{~g}$. DEX content in the supernatant was determined by HPLC. A reversedphase C18 column $(2.6 \mu \mathrm{m}, 50 \times 4.6 \mathrm{~mm}$ Phenomenex kinetex) was used. The mobile phase was acetonitrile/water at a pH $3(50 / 50 \mathrm{v} / \mathrm{v})$. The flow rate was $0.4 \mathrm{~mL} \mathrm{~min}^{-1}$ and the detection was obtained at $260 \mathrm{~nm}$ with a UV detector. The linear regression coefficient (R2) was determined in the range $0.01-30 \mu \mathrm{g} / \mathrm{mL}$ as $0.9993(\mathrm{n}=10)$.

Green analysis and energy consumption

Energy consumption calculation 
The energy consumption was evaluated considering the production with a DP/CP of $20 \%$. The energy required was calculated in terms of energy density $\left(\mathrm{Ev}, \mathrm{J} \mathrm{m}^{-3}\right)$, according to the following equation ${ }^{35}$ :

Equation 11: $\mathrm{Ev}=\frac{P}{Q_{E}}$

where $P$ stands for the effective power input (J S-1) and QE stands for the volume flow rate of the emulsion $\left(\mathrm{m}^{3} \mathrm{~s}^{-1}\right)$. Power input was calculated as follows:

Equation 12: $P=\left(\frac{\Delta P_{C P} * Q_{C P}}{\eta_{C P}}\right)$

Where $\Delta \mathrm{P}_{\mathrm{CP}}$ is the pressure drop along the membrane module, $\mathrm{Q}_{\mathrm{CP}}$ is the flow rate of the pump used to generate the pulsed flow and $\eta_{\mathrm{cp}}$ is the pump efficiency.

\section{Green factor calculation}

E factor is a simple analysis used to calculate the greenness of a process. Process waste was determined via complete $\mathrm{E}$ factor calculation based on a simple mass-balance ${ }^{4}$. Two factors were determined: simple $\mathrm{E}$ factor (sEF) and complete $\mathrm{E}$ factor (cEF) (in which solvent and water consumed during the process are also included) using equation 13 and equation 14, respectively, adapted to the specific case of particle production:

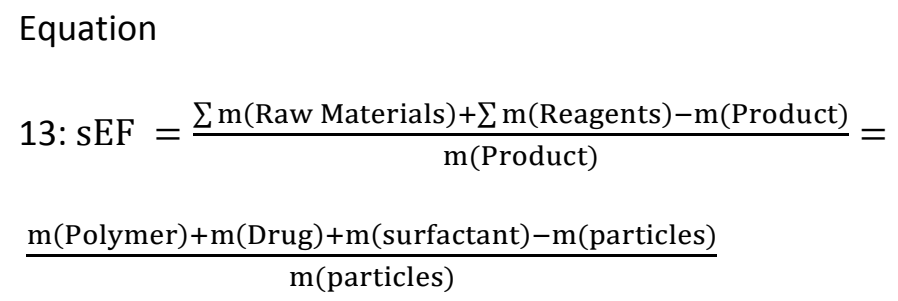


Equation 14:

$\frac{\sum \mathrm{m}(\text { Raw Materials })+\sum \mathrm{m}(\text { Reagents })+\sum \mathrm{m}(\text { Solvents })+\sum(\text { Water })-\mathrm{m}(\text { Product })}{\mathrm{m}(\text { Product })}=$ $\underline{\mathrm{m}(\text { Polymer })+\mathrm{m}(\text { Drug })+\mathrm{m}(\text { surfactant })+\mathrm{m}(\text { solvent })+\mathrm{m}(\text { water })-\mathrm{m}(\text { particles })}$ $\mathrm{m}$ (particles)

Where $\Sigma \mathrm{m}$ (Raw Materials) represents the total mass of polymer and drug used for producing a batch of product. $\Sigma \mathrm{m}$ (Reagent) represents the total mass of the reagents used in the process, principally the surfactant. $m$ (Product), $\Sigma m$ (solvent) and $\Sigma m$ (water) represent the masses of particles produced, mass of solvent and mass of water, respectively. CEF is used in GAL-based analysis enabling organizations to calculate their green performance scores.

The process mass intensity (PMI), calculated as the ratio of the total mass of materials to the mass of the product, has been selected from ACS Green Chemistry Institute Pharmaceutical Roundtable as indicator of sustainability for the pharmaceutical sector:

Equation 15: PMI $=\frac{\sum \mathrm{m}(\text { Materials input })}{\mathrm{m}(\text { Product })}=\mathrm{cEF}+1$

Where the $\Sigma m$ (Materials input) includes the total mass of polymer, drug, reagents used in the process (i.e., surfactant), mass of solvent and mass of water. The CEF and PMI can be used interchangeably in the GAL methodology ${ }^{36}$ and in this article, we will refer to it as CEF.

Percent's relation (\%cEF and \% solvent+water) was calculated using equation 16 and 17 :

Equation 16: $\% c E F=\frac{s E F}{c E F} * 100 \%$

Equation 17: \%solvent + water $=\frac{m(\text { solvent })+m(\text { water })}{m(\text { total })}$ 


\section{Results and Discussion}

\section{Effect of fluid-dynamic conditions during membrane emulsification process}

The fluid-dynamic conditions play an important role during particle manufacturing by membrane emulsification, determining the droplet size and droplet size distribution of the emulsion before the solidification step. The influence of the dispersed phase flux and shear stress on PLGA-PEG particle sizes and size distributions have been studied in order to identify the operation conditions that provide the smaller droplets with the highest uniformity and productivity. On the other hand, the dispersed phase flux and shear stress are strictly correlated with the throughput and energy consumption, respectively. These two parameters have also been evaluated in order to demonstrate the sustainability of the productive process.

\section{Effect of dispersed phase flux}

The effect of dispersed phase flux on PLGA-PEG particle size and particle size distribution has also been investigated. Figure $2 A$ describes the resulting particle sizes for $D[4,3], D[3,2]$ and span of PLGA-PEG microparticles produced by pulsed back-and-forward ME as a function of the dispersed phase flux in the range from 1.15 to $30.67 \mathrm{Lh}^{-1} \mathrm{~m}^{-2}$, keeping constant the maximum shear stress $(2.48 \mathrm{~Pa})$

Results demonstrated that the dispersed phase flux does not have a significant influence on particle size and span in the range from 1.15 to $12.84 \mathrm{Lh}^{-1} \mathrm{~m}^{-2}$. An average diameter (D[3,2]) and a span of distribution equal to $1.10 \mu \mathrm{m}$ and 0.50 were obtained, respectively. This flux range is identified as "dripping" regime ${ }^{31,34}$. The droplets are rapidly detached from the membrane surface and the contribution of the inertial force from the dispersed phase to the droplet sizes was negligible respect to the viscous drag and capillary forces. SEM images of the particles produced in this range are reported in Figure 2 (C1). The images reveal the homogenous size distributions and 
spherical shapes. An approximately linear increase in the particle size and span was observed when the dispersed phase flux was further increased in the range from 12.84 to $30.67 \mathrm{Lh}^{-1} \mathrm{~m}^{-2}$. A similar trend was previously reported in the literature for the production of other polymeric particles and emulsions. ${ }^{33,34,36}$ The formation of larger droplets was the result of the faster increase in the droplet growth as the dispersed phase flux was increased. At $18.02 \mathrm{~L} \mathrm{~h}^{-1} \mathrm{~m}^{-2}$ droplets were sheared off from the membrane surface before coalescence at the pore level. Uniform droplets $($ span $=0.8)$ were then produced although a slight increase in the droplet sizes was obtained $(D[3,2]=1.65 \mu \mathrm{m})$ (Figure 2, C2). The further increase of the dispersed phase flux generated less uniform (span $=1.6)$ and larger particles $(D[3,2]=3.6 \mu \mathrm{m})$ (Figure 2, C3).
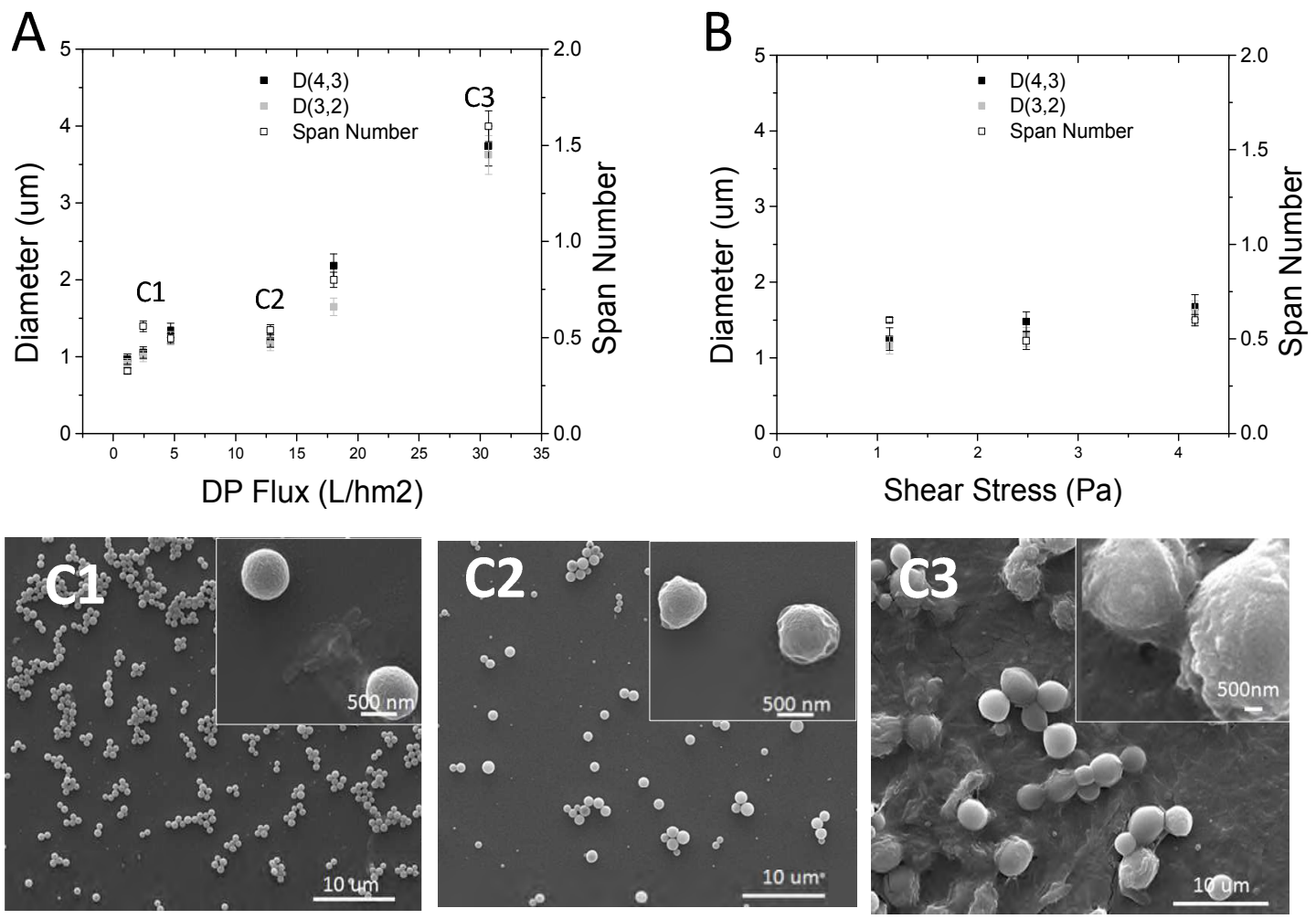

Figure 2. Effect of maximum shear stress and dispersed phase flux on particle size and particle size distribution at lower. A) Modification of dispersed phase flux at maximum shear stress of $2.48 \mathrm{~Pa}$. 
B) Modification maximum shear stress at dispersed phase flux of $2.5 \mathrm{Lh}^{-1} \mathrm{~m}^{-2} . \mathrm{C} 1, \mathrm{C} 2, \mathrm{C} 3 \mathrm{SEM}$ images of the particles represented in the graph

Results demonstrate that PLGA-PEG particles with sufficiently narrow distribution in the droplet size (span lower than 0.55 ) and mean diameter tending to the membrane pore diameter can be produced for dispersed phase fluxes in the range of 1.15 to $12.84 \mathrm{Lh}^{-1} \mathrm{~m}^{-2}$. The increase in the dispersed phase flow determines an increase in the throughput from $36.18 \mathrm{mg} \mathrm{h}^{-1}$ to $402 \mathrm{mg} \mathrm{h}^{-1}$ reducing the operation time from 1.38 to $0.12 \mathrm{~h}$. Data indicate that membrane emulsification can satisfy the demand of advanced manufacturing processes for industrial scale production by connecting efficiency and productivity. With their easy scale-up and large operational flexibility, membrane operations have been developed to the stage of large scale manufacture ${ }^{29}$ and membrane emulsification has also demonstrated its capability for large scale industrial operations 37.

Effect of maximum shear stress

In pulsed back-and-forward ME, the shear stress is a function of the frequency and the amplitude of the pulsation along the lumen side of the membrane. The amplitude of the pulsation was kept constant $(47.1 \mathrm{~mm})$ while the increase of the continuous phase flow rate in the range from 500 to $1200 \mathrm{~mL} \mathrm{~min}^{-1}$ determined an increase in the frequency from 1.49 to $3.57 \mathrm{~Hz}$. Figure 2B shows the effect of the maximum wall shear stress on PLGA-PEG particle size and particle-size distribution. Particle size (mean droplet diameter $=1.25 \pm 0.13 \mu \mathrm{m}$ ) was not significantly influenced as the shear stress was increased in the range of values investigated (from 1.12 to $4.16 \mathrm{~Pa}$ ). Typically, the mean particle decreases sharply as the wall shear stress increases and reaches a size where it 
becomes more or less independent of the shear. This effect is decreased in case of the production of submicron droplets and relatively small droplets are produced at lower shear stress.

The development of environmentally benign methods for manufacturing processes has become increasingly relevant in the last years determining a significant expansion in the development of more energy-efficient methodologies. Unutilized energy may be considered as a waste and the design of manufacturing processes that do not require intensive energy use is highly desirable. Membrane emulsification is a valuable technology to asses this goal. In the present work, the energy consumption used during the membrane emulsification process was reduced in the range from $9.5010^{5}$ to $3.9010^{5} \mathrm{Jm}^{-3}$ as the maximum shear stress was decreased from 4.16 and $1.12 \mathrm{~Pa}$. Considering that a shear stress of $1.12 \mathrm{~Pa}$ was enough to produce uniform particles (span $=0.6$ ) with $D[3,2]$ of $1.17 \mu \mathrm{m}$ (tending to the membrane pore size), the further increase of the shear stress was not needed minimizing also energy consumption. Furthermore, traditional emulsification techniques are known to be rather energy consuming ${ }^{38,39}$. The energy consumption associated with the use of an homogenizer, a sonicator and a magnetic stirrer is $10^{6}-10^{8} \mathrm{Jm}^{-3} 40$ that is 1-3 orders of magnitude higher that the value measured in the present work.

Results clearly indicate that membrane emulsification allows operating under mild conditions to generate uniform droplets with mean diameters tending to the pore diameter reducing, at the same time, energy consumption.

\section{Effect of process conditions used in the solidification step}

In the production of PLGA-PEG microparticles by membrane emulsification- solvent diffusion method, both the organic solvent phase, in which the polymer is dissolved, and the aqueous continuous phase saturated with the organic solvent, are in the state of thermodynamic equilibrium. The addition of a certain volume of continuous phase to the system destabilizes the 
equilibrium. It causes the organic solvent to diffuse to the external phase and precipitates the polymer to form the solidified particles. Solvent removal determines droplet volume reduction by a shrinkage factor given by the chemical composition of the organic phase and defined as the ratio between the liquid droplet diameter and the solidified particle diameter ${ }^{41}$.

The effect of the type of organic phase solvents (EA or DCM) and solidification diffusion velocity on PLGA-PEG mean particle size, size distribution and particle morphology were investigated. On the other hand, for drug encapsulation, it is required that all the chemicals are used (such as solvents, polymer, and reagents) reducing or eliminating the generation of undesirable products that could be harmful both for human health and the environment. For that reason, sEF and cEF were evaluated for each chemical used in the production of PLGA-PEG microparticles.

\section{Effect of organic solvent phase}

Variations in particle size and particle morphology were observed when different organic solvents were used in the preparation of PLGA-PEG microparticles by the membrane emulsification/solvent diffusion method. Figure $3 \mathrm{~A}$ reports the average diameter and span of PLGA-PEG particles produced by using EA or DCM as polymer solvent while SEM images of PLGA-PEG particles are reported in Figure $3 C$. More heterogeneous particles (span $=0.95$ ) with an average diameter of three times the pore size of the membrane $(D[3,2]=3.15 \mu \mathrm{m})$ were obtained when $D C M$ was used. SEM images confirmed the heterogeneous distribution of the particles and revealed the presence of large holes and protuberances on the particles (Figure 3C1). On the contrary, uniform particles $(\operatorname{span}=0.62)$ with an average diameter close to the pore size of the membrane $(D[3,2]=1.25 \mu \mathrm{m})$ were produced by using EA. SEM images show a dense and slightly rough surface without pores (Figure $3 \mathrm{C} 2$ ). The differences observed in terms of particle-size distribution and morphology are strictly correlated with the solvent solubility in the water phase. The miscibility of the solvent in 
water influences the diffusion velocity and has a direct impact on the final size of the particles ${ }^{20}$. EA has a water miscibility $\left(\mathrm{S}_{\mathrm{EA}}=9.7 \mathrm{wt} \%\right) 4.5$ times higher than DCM and, as a result, EA-Water interfacial tension $\left(6.8 \pm 0.6 \mathrm{mN} \mathrm{m}^{-1}\right)$ is significant lower than DCM-Water interfacial tension $(28.28$ $\left.\pm 0.40 \mathrm{~m} \mathrm{Nm}^{-1}\right)^{42,43}$. In addition, since PLGA-PEG microparticles are formed from the emulsion droplets after organic solvent diffusion, emulsion droplets stability plays an important role to tune the properties of the structured particles. Uniform and smaller particles produced by using EA resulted from both the ability of the emulsifier (Pluronic P127) to prevent droplet coalescence, and the low interfacial tension between the aqueous and the organic phases, due to the partially water-soluble nature of EA. On the contrary, the boiling point of DCM is lower than the one of EA, allowing a flash solvent evaporation. Its miscibility with water is also lower, delaying solvent diffusion and increasing the solidification time. This determines the formation of pores and holes (Figure $3 \mathrm{C} 1$ ) as well as droplet aggregation probably responsible for the production of larger mean particle sizes. Similar results were found by Song et al. using PLGA as polymer, EA and DCM as solvents and Dimethylamine borane (DMAB) as surfactant ${ }^{20}$. 


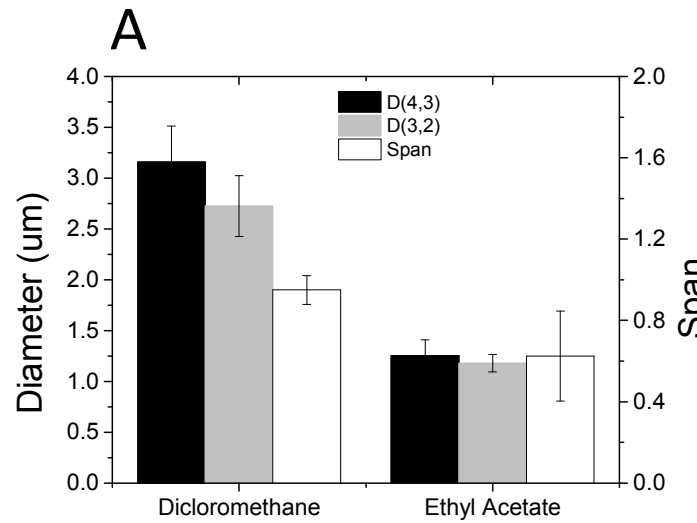

Solvent

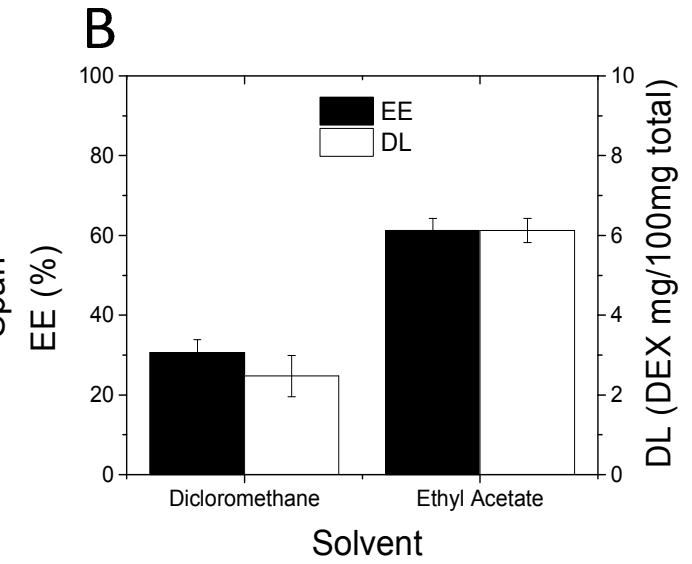

Solvent
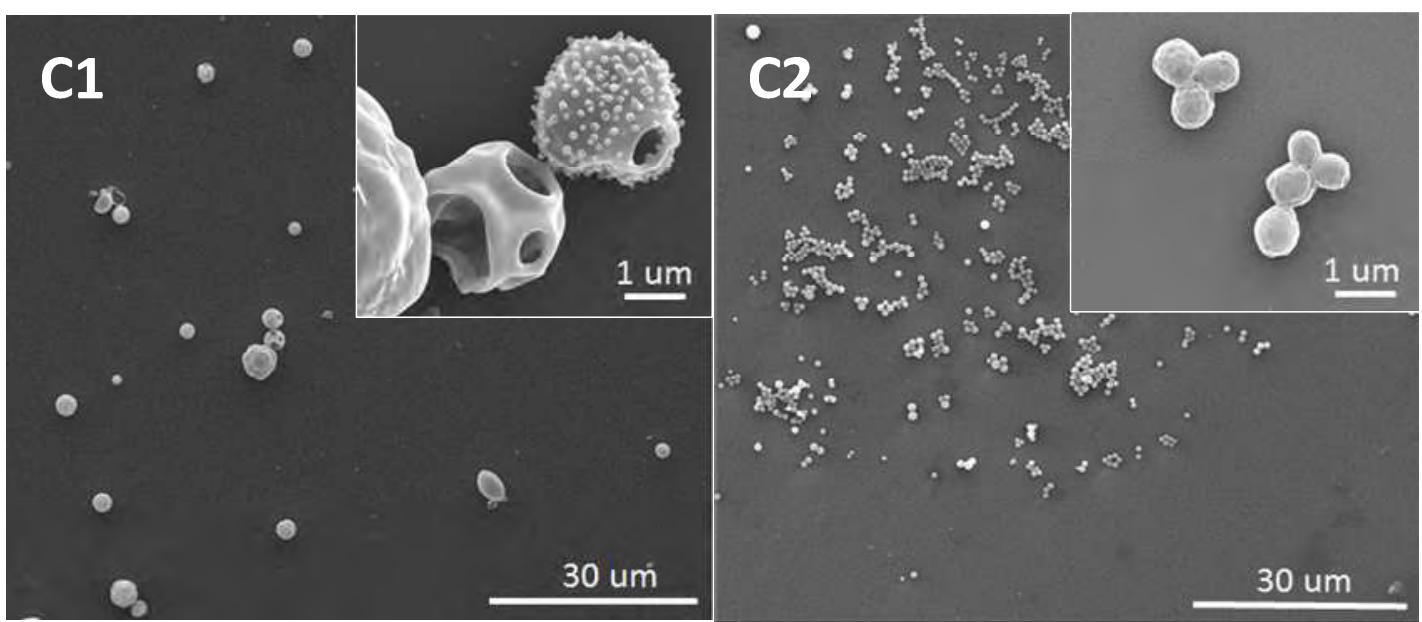

Figure 3. The effect of organic solvent type on A) particle size, particle-size distribution of particles.

B) EE and DL (membrane emulsification/ solvent diffusion) and on particles morphology. C) (Polymer: PLGA-PEG, Surfactant: Pluronic, Vd/Vth=3, PTM/Pc=1.20, Shear stress: 2.48Pa ). C1) SEM image of the particles PLGA-PEG particles produced with DCM. C2) SEM image of the particles PLGA-PEG particles produced with EA.

EE and DL were also evaluated (Figure 3B). The use of EA improves the encapsulation efficiency up to $50 \%$ respect to the use of DCM. The analysis of the particle morphology previously discussed can suggest that the porous surface of PLGA-PEG particles produced with DCM determined the enhanced leakage of the dexamethasone into the continuous phase. Similar results were 
previously reported by Imbrogno et al. for porous particles produced by using Polycaprolactone as polymer and DCM as solvent ${ }^{44}$. The use of EA also improved DL up to $50 \%$ reducing the content of the carrier material ${ }^{45}$ minimizing waste generation and improving production profitability. For that reason, SEF and cEF values and particle costs were evaluated in this section (Table 1).

The generation of any material that does not have realizable value, such as the non-encapsulated drug, can be considered as a waste. The non-encapsulated drug may affect the environment differently depending on its nature, toxicity or dose. On the other hand, maximizing the use of raw materials (such as drugs and carrier materials) so that the final formulation contains the maximum number of atoms coming from the reactants is the key point to design an efficient and sustainable manufacturing process.

SEF and CEF values were calculated when EA or DCM were used as organic solvents (Table 1). The evaluation of $\mathrm{SEF}$ and $\mathrm{CEF}$ plays a major role when focusing the attention on the problem of waste generation in pharmaceutical particle manufacturing and provides the impetus for developing cleaner and more sustainable processes. SEF and cEF values were reduced by $80 \%$, when EA was used compared to DCM.

Table 1. The effect of organic solvent type and solidification velocity on green metric factors in memrane emulsification/solvent diffusion

\begin{tabular}{|c|c|c|c|c|c|c|}
\hline & Solvent & DCM & EA & EA & EA & EA \\
\hline & Vd/Vth & $\mathbf{3}$ & $\mathbf{3}$ & $\mathbf{1}$ & $\mathbf{0 . 5}$ & $\mathbf{0}$ \\
\hline \multirow{3}{*}{$\begin{array}{c}\text { Green } \\
\text { Analysis }\end{array}$} & $\mathrm{sEF} \mathrm{(mg/mg)}$ & 290.99 & 59.18 & 23.66 & 14.78 & 5.90 \\
\cline { 2 - 7 } & cEF cEF litd & 25503.38 & 5237.41 & 2140.03 & 1365.69 & 591.35 \\
\cline { 2 - 7 } & \% solvent + water & $98.86 \%$ & $98.85 \%$ & $98.85 \%$ & $98.85 \%$ & $98.84 \%$ \\
\hline
\end{tabular}




\begin{tabular}{|c|c|c|c|c|c|c|}
\hline \multirow{6}{*}{$\begin{array}{l}\text { Economic } \\
\text { Analysis }\end{array}$} & $\begin{array}{c}\text { Polymer Price } \\
\text { (Euros/g product) }\end{array}$ & \multicolumn{5}{|c|}{50.00} \\
\hline & Drug Price(Euros/g & \multicolumn{5}{|c|}{34.50} \\
\hline & $\begin{array}{l}\text { Surfactant Price } \\
\text { (Euros/g product) }\end{array}$ & 581.78 & 118.15 & 47.12 & 29.36 & 11.60 \\
\hline & $\begin{array}{c}\text { Solvent Price } \\
\text { (Euros/g product) }\end{array}$ & 0.57 & \multicolumn{4}{|c|}{0.54} \\
\hline & $\begin{array}{c}\text { Water Price (Euros/g } \\
\text { product) }\end{array}$ & 25.07 & 5.04 & 1.98 & 1.22 & 0.45 \\
\hline & $\begin{array}{c}\text { Total (Euros/g } \\
\text { product) }\end{array}$ & 691.92 & 208.23 & 134.14 & 115.61 & 97.09 \\
\hline
\end{tabular}

Table 1 summarizes the economic analysis and the breakdown of the chemical reagents involved in the production of Dexamethasone loaded PLGA-PEG particles. Particle cost was reduced by 70\%, when EA was used compared to DCM using $V_{d} / V_{\text {th }}=3$ (Table 1 ) as a result of the low amount of water and emulsifier required to obtain particle solidification when using EA. When particle solidification occurs by solvent diffusion, solvent solubility strictly influences the amount of nonsolvent (i.e., water) and surfactant required for solvent-non-solvent exchange ${ }^{7}$. EA is more soluble in water than DCM and the amount of water and surfactant required for droplet solidification is lower (Table I). This difference is the main reason to explain why costs were reduced for PLGA-PEG particles produced at the same Vd/Vth ratio with EA (208.23 Euros/g product) and DCM (691.92 Euros/g product ). In addition, EA results to be a greener solvent for the production of drug delivery systems based on PLGA-PEG considering both its E factor and its low toxicity. Several researchers have analyzed the toxicity on human cell lines of PLGA-PEG particles produced using EA as a solvent, observing that particles do not alter cell proliferation. This indicates that the PLGA delivery systems prepared by using EA are nontoxic at the doses used ${ }^{46-48}$. 


\section{Solidification diffusion velocity}

The influence of $V_{d} / V_{t h}$ ratio on PLGA-PEG particle size and span is presented in Figure 4 . The solidification rate of the emulsion droplets is directly related to the solvent diffusion volume. Results indicate that particle sizes were almost independent on $V_{d} / V_{\text {th }}$ ratio. Uniform particles (span $<0.60$ ) with an average diameter of $1.25 \mu \mathrm{m}$ were produced (Figure $4 \mathrm{~A}, 4 \mathrm{C}$ ). EA has a low vapour pressure that makes its evaporation very fast (EA Vapor Pressure: 0.13 bar at $25^{\circ} \mathrm{C}$ ). This promotes the solidification process because the emulsification-diffusion method guarantees the free solvent diffusion as long as the organic solvent solubility condition is satisfied ${ }^{49}$. Considering the partially water-soluble nature of EA, its fast diffusion from the droplets was expected.

DEX EE was decreased from $61.22( \pm 3.00) \%$ to $57.12( \pm 3.56) \%$ when the $V_{t h} / V_{0}$ was increased from 0 to 3 (Figure 4B) as a result of the increase in the concentration gradient of the encapsulated DEX toward the external aqueous phase during the solidification process ${ }^{25}$.

Green metric factors were calculated and are presented in Table 1. SEF and CEF values were reduced by $90.03 \%$, when $\mathrm{V}_{\mathrm{d}} / \mathrm{Vt}_{\mathrm{h}}=0$ (no diffusion solution added) was used compared to $\mathrm{V}_{\mathrm{d}} / \mathrm{Vt}_{\mathrm{h}}=3$. Data indicate that the use of EA allowed reducing the water consumption and the surfactant amount used in the solidification step. This determines also a cost reduction of $53.38 \%$ as a function of $V_{d} / V t_{h}$ (from 3 to 0 ). (Table 1 ). 
A

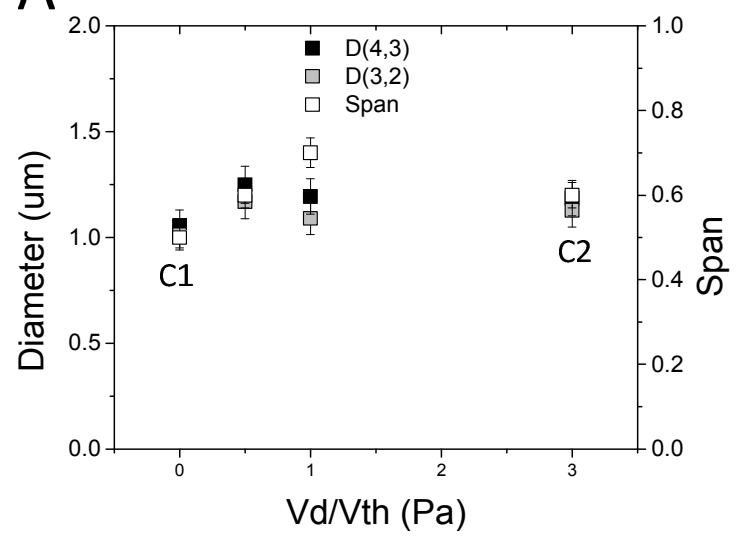

B

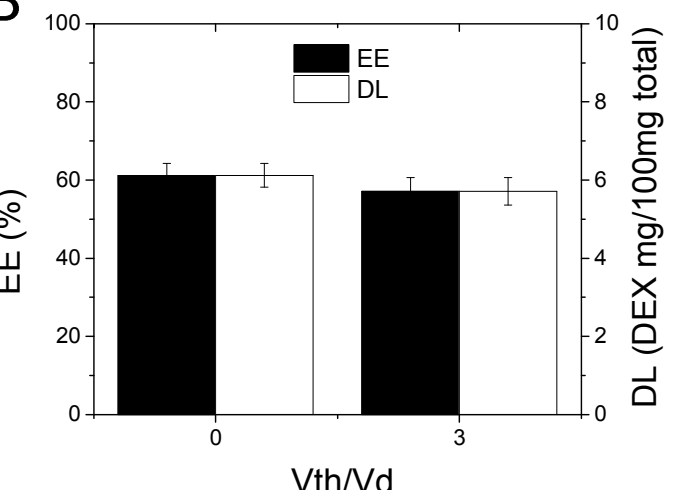

Vth/Vd
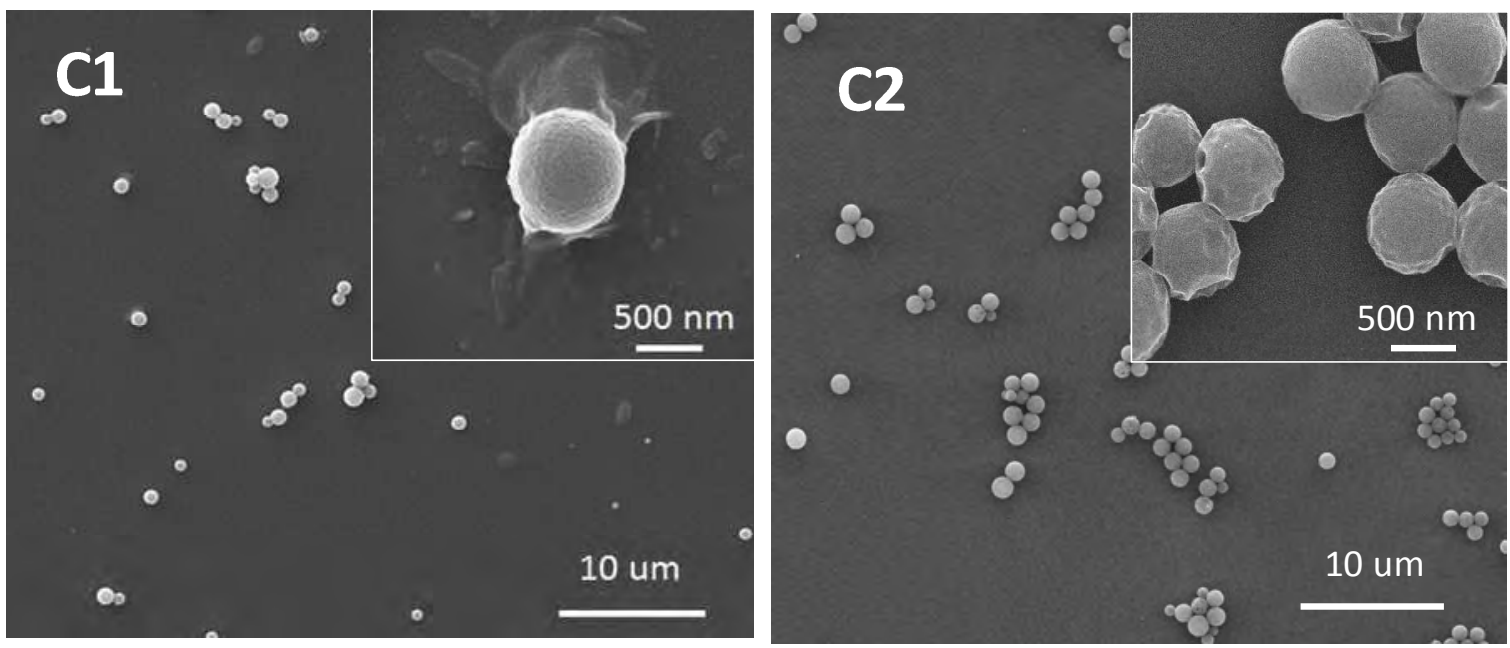

Figure 4. The effect of solidification velocity on A) particle size, particle-size distribution of particles, B) EE and DL (membrane emulsification/ solvent diffusion) and on particles morphology C) (Polymer: PLGA-PEG, Surfactant: Pluronic, Organic solvent: $E A, P T M / P c=1.2$, Shear stress: 2.48Pa ). C1) SEM image of the particles PLGA-PEG particles produced with Vt/Vo =0. C2) SEM image of the particles PLGA-PEG particles produced with $\mathrm{Vt} / \mathrm{Vo}=3$.

In the present work, the production of PLGA-PEG particles as potential drug delivery vectors was assessed by using membrane emulsification/solvent diffusion method. The optimized operative conditions during the emulsification (DP flux $=12.84 \mathrm{Lh}^{-1} \mathrm{~m}^{-2}$, shear stress $=1.12 \mathrm{~Pa}$ ) and the solidification steps (solvent $=\mathrm{EA}, \mathrm{Vd} / \mathrm{Vth}=0$ ) allowed to produce uniform particles $(\mathrm{span}=0.62)$ with an average particle size of $1.25 \mu \mathrm{m}$ and an EE of $61.22 \%$. High throughput was achieved by 
increasing the dispersed phase flux to $12.84 \mathrm{Lh}^{-1} \mathrm{~m}^{-2}$ in mild operative conditions (shear stress $=$ $1.12 \mathrm{~Pa})$ reducing at the same time the energy consumption $\left(3.96 .10^{5} \mathrm{Jm}^{-3}\right)$. EA resulted to be a valuable alternative solvent for PLGA particle production as being a greener solvent considering both green metric factors and toxicity compared to the use of DCM. The use of EA makes the particle production process more sustainable reducing the volume of water consumed and the amount of emulsifier used. This allowed also decreasing the economic impact of these components.

\section{A comparison with the literature}

Recent works on the production of PLGA-PEG particles by emulsification-solvent diffusion method is analysed in this section with the aim to demonstrate the sustainability of the manufacturing method used in the present work. The use of membrane-emulsification in the preparation of PLGA particles has been previously reported ${ }^{50-53}$ however; the greenness of this process has not been measured.

Energy density and process throughput obtained in the present work are compared with data calculated from previous works in which membrane-based processes ${ }^{50,53}$ and also conventional emulsification methods ${ }^{7,9,49}$ have been used during PLGA particle production (Table 2). Considering the similar physicochemical properties of PLGA and PLGA-PEG polymers ${ }^{49}$, literature data about PLGA particles manufacturing were used for the comparison according to the availability of all the information required for throughput and energy density calculations (see supplementary materials section).

One of the frequently mentioned advantages of membrane emulsification over conventional emulsification methods is the lower energy density requirement ${ }^{54}$. The concept of energy density has been previously applied to compare different mechanical emulsifying processes ${ }^{54,55}$. The 
comparison illustrates that, given equal energy densities, different emulsifying equipment (rotorstator systems, ultrasound systems, high-pressure homogenizers and membrane emulsifiers) produces very different droplet sizes. In membrane emulsification, particles with a mean diameter approximately equal to were produced with an energy density in the range of $10^{3}-10^{6} \mathrm{Jm}^{-3}$ which is 1-2 orders of magnitude smaller than in high-pressure valve homogenizers ${ }^{54}$. In the present work, we compared the energy density required for the production of PLGA particles by using different mechanical emulsifying processes. The comparison illustrates that only the pulsed back-andforward method allowed decreasing effectively the energy density respect to the other conventional emulsification methods. It is well known that higher energy densities are needed to produce smaller droplets ${ }^{54,55}$. For that reason, results obtained in the present work by using the pulsed back-and-forward method are more relevant if we consider that the mean particle size $(1.25 \mu \mathrm{m})$ is significantly smaller that the size reported by other membrane emulsification methods $(60-120 \mu \mathrm{m}){ }^{50}$ or by conventional emulsification methods $(15-80 \mu \mathrm{m}){ }^{15,56,57}$. Slightly smaller particles (mean particle size $=$ 0.4-0.6 $\mu \mathrm{m}$ ) with high throughput $\left(310^{-7} \mathrm{~m}^{3} \mathrm{~s}^{-1}\right)$ were produced by using the sonicator in the emulsification step but with a significant increase in the energy consumption (from $10^{5} \mathrm{Jm}^{-3}$ by using pulsed-back-and-forward membrane emulsification to $10^{8} \mathrm{Jm}^{-3}$ by using a sonicator). ${ }^{40}$ Pulsed back-and-forward membrane emulsification appears to be an alternate valuable method with low energy consumption ( 3 orders of magnitude lower) respect to other membrane emulsification methods of operation for the production of particles in the same range of $\operatorname{sizes}^{53}$ although the process throughput was one order of magnitude lower than those associated with the conventional emulsification methods. 
Table 2. Comparison between the membrane emulsification/solvent diffusion process and processes described in the literature

\begin{tabular}{|c|c|c|c|c|c|c|c|c|}
\hline & & \multicolumn{3}{|c|}{ MEMBRANE EMULSIFICATION } & \multicolumn{4}{|c|}{ CONVENTIONAL EMULSIFICATION METHOD } \\
\hline & & Present Work & $\begin{array}{l}\text { Ho et al, } \\
2013^{53}\end{array}$ & $\begin{array}{l}\text { Gasparini et } \\
\text { al, } 2008^{50}\end{array}$ & $\begin{array}{c}\text { Kim and } \\
\text { Martin, } 2006^{58}\end{array}$ & $\begin{array}{l}\text { Gu and Burgess, } \\
2015^{15}\end{array}$ & $\begin{array}{l}\text { Park et al, } \\
2009^{56}\end{array}$ & $\begin{array}{l}\text { Goodfriend et al, } \\
2016^{57}\end{array}$ \\
\hline \multirow{6}{*}{$\begin{array}{l}\text { Chemical } \\
\text { Composition }\end{array}$} & Polymer & PLGA-PEG & PLGA & PLGA & PLGA & PLGA & PLGA & PLGA \\
\hline & Drug & DEX & curcumin & $\mathrm{N} / \mathrm{A}$ & DEX & DEX & DEX & DEX \\
\hline & Solvent & EA & Chloroform & DCM & DCM/Acetone & DCM & DCM & Tetrahydrofuran \\
\hline & Surfactant & Pluronic F127 & PVA & PVA & PVA & PVA & PVA & Pluronic F127 \\
\hline & $\begin{array}{c}\text { Dispersed Phase/Continuous } \\
\text { Phase ratio }\end{array}$ & 0.20 & 0.10 & 0.07 & 0.20 & 0.20 & 0.10 & 1.00 \\
\hline & Total Volume $(\mathrm{mL})$ & 30.00 & 6.60 & 160.00 & 180.00 & 137.00 & 330.00 & 10.00 \\
\hline \multirow{3}{*}{$\begin{array}{c}\text { Emulsification } \\
\text { Process }\end{array}$} & Membrane & $\begin{array}{c}\text { SPG } \\
\text { Membrane } \\
D_{p}=1 u m\end{array}$ & $\begin{array}{c}\text { Silicon } \\
\text { nitride } \\
\text { membrane } \\
D_{p}=2 u m\end{array}$ & $\begin{array}{l}\text { Metallic } \\
\text { membrane } \\
D_{p}=40 u m\end{array}$ & - & - & - & - \\
\hline & Emulsification Device & $\begin{array}{l}\text { Cross-Flow } \\
\text { pulsed back- } \\
\text { and-forward }\end{array}$ & Cross-Flow & Stirred & $\begin{array}{l}\text { Sonicator } \\
\text { (Fisher 500) }\end{array}$ & $\begin{array}{c}\text { T } 25 \text { digital } \\
\text { ULTRA-TURRAX } \\
\text { homogenizer }\end{array}$ & $\begin{array}{l}\text { Magnetic } \\
\text { stirrer }\end{array}$ & Vortexed stirrer \\
\hline & Throughput (m3 s-1) & $1.32 * 10^{-08}$ & $2.20 * 10^{-08}$ & $1.33 * 10^{-07}$ & $3.00 * 10^{-07}$ & $2.00 * 10^{-07}$ & $5.50 * 10^{-07}$ & $5.56 * 10^{-09}$ \\
\hline \multirow{3}{*}{$\begin{array}{c}\text { Formulation } \\
\text { Properties }\end{array}$} & Mean Particle size (um) & 1.25 & 2.30 & 60.00 & $0.40-0.60$ & 15.00 & 20.00 & 50.00 \\
\hline & EE \% & 61.20 & 32.00 & $\mathrm{~N} / \mathrm{A}$ & $79.00 \pm 5.00$ & $70-95$ & $\mathrm{~N} / \mathrm{A}$ & 60.00 \\
\hline & DL \% & 6.16 & 2.00 & $\mathrm{~N} / \mathrm{A}$ & $13.00 \pm 3.00$ & 10 & $\mathrm{~N} / \mathrm{A}$ & $\mathrm{N} / \mathrm{A}$ \\
\hline $\begin{array}{c}\text { Energy } \\
\text { Consumption }\end{array}$ & Energy density (Jm-3) & $3.96 * 10^{-05}$ & $2.29 * 10^{-08}$ & $2.25 * 10^{-08}$ & $2.00 * 10^{-08}$ & $1.60 * 10^{-09}$ & $1.09 * 10^{-08}$ & $2.52 * 10^{-08}$ \\
\hline \multirow{4}{*}{ Green Analysis } & sEF & 5.90 & & & & 0.71 & & \\
\hline & $\mathrm{cEF}$ & 591.35 & & & & 313.17 & & \\
\hline & $\%$ cEF litd & $1.00 \%$ & & & & $0.23 \%$ & & \\
\hline & $\%$ solvent + water & $98.84 \%$ & & & & $99.45 \%$ & & \\
\hline \multirow{3}{*}{$\begin{array}{c}\text { Economic } \\
\text { Analysis }\end{array}$} & $\begin{array}{c}\text { Polymer Price (Euros/g } \\
\text { product) }\end{array}$ & 50.00 & 50.00 & 50.00 & 50.00 & 50.00 & 50.00 & 50.00 \\
\hline & Drug Price(Euros/g product) & 34.50 & 34.50 & $\mathrm{~N} / \mathrm{A}$ & 86.25 & 70.38 & 3.45 & 215.63 \\
\hline & Total Cost (Euros/g product) & 97.09 & 106.09 & 52.14 & 155.35 & 121.73 & 56.56 & 265.68 \\
\hline
\end{tabular}


Green metric factors obtained for the method developed in the present work were compared with the same data calculated for the method described by Gu and Burgess ${ }^{15}$. This paper was the only one that included data referred to both emulsification and solvent diffusion steps, while other papers analysed in this section only referred to the emulsification step ${ }^{50,53,56-58} \mathrm{sEF}$ and $\mathrm{CEF}$ resulted to be quite similar and the most important difference was attributed to the amount of polymer and drug used. The ratio between $\mathrm{SEF}$ and $\mathrm{cEF}$ values (\% cEF litd) is a helpful indicator for relative solvent usage and thus waste reduction potential. The low \% cEF litd value (lower than $1 \%$ ) and the relative value of solvent and water percentages higher than $95 \%$ indicated that, solvents (organic solvent and water) are the most utilized material in the production of polymer particles via emulsification and solvent diffusion.

Similar analysis previously conducted in the pharmaceutical field confirms the higher contribution of solvents to the cumulative PMI. The relative value of solvent and water percentages associated with the production of active ingredients from a survey of several pharmaceutical companies was estimated to be $88 \%$ by the Pharmaceutical Roundtable ${ }^{57}$. In contrast, the results for the commercial route show a lower relative value of solvent and water percentage solvent of $78 \%^{58}$. Anyway, the environmental impact of the solvent depends on the environmental factor and the solvent type as previously discussed.

Solvents used for the production of PLGA particles included in Table 2 are DCM ${ }^{50,56,58}$ and chloroform ${ }^{53}$. Both, Chloroform and DCM have been classified as Class 2 with a permissible concentration of $60 \mathrm{ppm}$ for Chloroform and (lower than that allowed for DCM) ${ }^{59}$. EA is classified as a Class 3 solvent and then it results a greener solvent respect to the solvents previously used in PLGA particles production. EQ-factor (environmental quotient factor) was proposed as a valuable extension of E-factor in order to consider the toxicity of materials and it is obtained by multiplying the $E$ factor with an arbitrarily assigned unfriendliness quotient, $Q$. However, the magnitude of $Q$ is 
currently debatable and difficult to quantify and this hampers the correct assessment of a green analysis. ${ }^{60}$ Several general purpose solvents, ${ }^{22}$ analyzing the most conventional solvents taking into account the European regulation concerning the 'Registration, Evaluation, Authorisation and Restriction of Chemicals' (REACH) and the recommendations of pharmaceutical industry solvent selection guides identified EA as recommended/preferred solvent while Chloroform and DCM as undesirable.

The economic analysis performed demonstrates that the cost of the microparticles was 97.09euro/g of particles produced. It is important to point out that in the calculation only the raw material costs are included, however, the calculation helps to identify the components influencing most significantly the cost of particle production. Main cost components result to be the polymer (51.15\%) and the drug (35.45\%) as reported also in previous works ${ }^{15,50,53,56-58}$.

About the formulation properties, it is notable that EE and DL for DEX encapsulation previously reported in Table 2 were close to those obtained in the present work. This indicates that the encapsulation efficiency is not correlated with the emulsification method used. EE and DL are highly dependent on the polymer and drug initial amounts, surfactant type, concentration and solvent type ${ }^{15,49}$. A low initial amount of drug used in the present work $\left(1 \mathrm{mg} \mathrm{L}^{-1}\right)$ is responsible for a lower $\mathrm{EE}$ obtained respect to other data reported in Table 2 (EE $=70 \%$, initial drug concentration $=6.66 \mathrm{mg} \mathrm{L}^{-158}$ and $44.93 \mathrm{mg} \mathrm{L}^{-115}$ ).

The simplicity and versatility of the membrane emulsification method combined with the use of green solvents hold much promise for the development of a sustainable chemical manufacturing industry. Considering that a broad spectrum of micro-nanostructured materials with predictable and controllable sizes, different chemical compositions, morphologies, and functionalities can be produced by using the proposed method, membrane-based technologies result the best green process choice. 


\begin{abstract}
Associated content
Full details about the intensification analysis (mass balance, economic, green analysis and energy consumption) of the described process are provided in the Supplementary Information.
\end{abstract}

\title{
Acknowledgments
}

The authors thank financial support from the ERC Consolidator Grant program (ERC-2013- CoG614715, NANOHEDONISM). CIBER-BBN is an initiative funded by the VI National R\&D\&i Plan 20082011 financed by the Instituto de Salud Carlos III with the assistance of the European Regional Development Fund. Program Erasmus Mundus Doctorate in Membrane Engineering-EUDIME (2011-0014) is grate fully acknowledged. The authors acknowledge for the financial support the project PON01_01545, Olio più, within the framework PON Ricerca e Competitività 2007-2013. 


\section{References}

(1) Albisa, A.; Español, L.; Prieto, M.; Sebastian, V. Polymeric Nanomaterials as Nanomembrane Entities for Biomolecule and Drug Delivery. Curr. Pharm. Des. 2016, 23, 263-280.

(2) Boodhoo, K.; Harvey, A. Process Intensification Technologies for Green Chemistry Engineering Solutions for Sustainable Chemical Processing; Wiley: Chichester, 2013.

(3) Etheridge, M. L.; Campbell, S. A.; Erdman, A. G.; Haynes, C. L.; Wolf, S. M.; McCullough, J. The Big Picture on Nanomedicine: The State of Investigational and Approved Nanomedicine Products. Nanomedicine Nanotechnol. Biol. Med. 2013, 9 (1), 1-14.

(4) Roschangar, F.; Colberg, J.; Dunn, P. J.; Gallou, F.; Hayler, J. D.; Koenig, S. G.; Kopach, M. E.; Leahy, D. K.; Mergelsberg, I.; Tucker, J. L.; et al. A Deeper Shade of Green: Inspiring Sustainable Drug Manufacturing. Green Chem 2017, 281-285.

(5) Sainz, V.; Conniot, J.; Matos, A. I.; Peres, C.; Zupančič, E.; Moura, L.; Silva, L. C.; Florindo, H. F.; Gaspar, R. S. Regulatory Aspects on Nanomedicines. Biochem. Biophys. Res. Commun. 2015, 504-510.

(6) Pramod, K.; Tahir, Ma.; Charoo, N.; Ansari, S.; Ali, J. Pharmaceutical Product Development: A Quality by Design Approach. Int. J. Pharm. Investig. 2016, 6 (3), 129.

(7) Li, M.; Rouaud, O.; Poncelet, D. Microencapsulation by Solvent Evaporation: State of the Art for Process Engineering Approaches. Int. J. Pharm. 2008, 363 (1-2), 26-39.

(8) Chan, J. M.; Valencia, P. M.; Zhang, L.; Langer, R.; Farokhzad, O. C. Polymeric Nanoparticles for Drug Delivery. In Cancer Nanotechnology; Grobmyer, S. R., Moudgil, B. M., Eds.; Humana Press: Totowa, NJ, 2010; Vol. 624, pp 163-175.

(9) Makadia, H. K.; Siegel, S. J. Poly Lactic-Co-Glycolic Acid (PLGA) as Biodegradable Controlled Drug Delivery Carrier. Polymers 2011, 3 (4), 1377-1397.

(10) Xu, Q.; Ensign, L. M.; Boylan, N. J.; Schön, A.; Gong, X.; Yang, J.-C.; Lamb, N. W.; Cai, S.; Yu, T.; Freire, E.; et al. Impact of Surface Polyethylene Glycol (PEG) Density on Biodegradable Nanoparticle Transport in Mucus Ex Vivo and Distribution in Vivo. ACS Nano 2015, 9 (9), 9217-9227.

(11) Urbańska, J.; Karewicz, A.; Nowakowska, M. Polymeric Delivery Systems for Dexamethasone. Life Sci. 2014, 96 (1-2), 1-6.

(12) Cohen, E. M. Dexamethasone. In Analytical Profiles of Drug Substances; Elsevier, 1973; Vol. 2, pp 163-197.

(13) Krishnan, V.; Xu, X.; Barwe, S. P.; Yang, X.; Czymmek, K.; Waldman, S. A.; Mason, R. W.; Jia, X.; Rajasekaran, A. K. Dexamethasone-Loaded Block Copolymer Nanoparticles Induce Leukemia Cell Death and Enhance Therapeutic Efficacy: A Novel Application in Pediatric Nanomedicine. Mol. Pharm. 2013, 10 (6), 2199-2210.

(14) Campos, I. M. F.; Santos, T. M.; Cunha, G. M. F.; Silva, K. M. M. N.; Domingues, R. Z.; da Silva Cunha Júnior, A.; de Souza Figueiredo, K. C. Preparation and Release Characteristics of Dexamethasone Acetate Loaded Organochlorine-Free Poly(Lactide- Co-Glycolide) Nanoparticles. J. Appl. Polym. Sci. 2014, 131 (23), 1-6.

(15) Gu, B.; Burgess, D. J. Prediction of Dexamethasone Release from PLGA Microspheres Prepared with Polymer Blends Using a Design of Experiment Approach. Int. J. Pharm. 2015, 495 (1), 393-403.

(16) Roy, W. R. Environmental Impact of Solvents. In Handbook of Solvents; Elsevier, 2014; pp 361-412. 
(17) Sah, H. Microencapsulation Techniques Using Ethyl Acetate as a Dispersed Solvent: Effects of Its Extraction Rate on the Characteristics of PLGA Microspheres. J. Controlled Release 1997, 47 (3), 233-245.

(18) Bahl, Y.; Sah, H. Dynamic Changes in Size Distribution of Emulsion Droplets during Ethyl Acetate-Based Microencapsulation Process. AAPS PharmSciTech 2000, 1 (1), 41-49.

(19) Soppimath, K. S.; Aminabhavi, T. M. Ethyl Acetate as a Dispersing Solvent in the Production of Poly(DL-Lactide-Co-Glycolide) Microspheres: Effect of Process Parameters and Polymer Type. J. Microencapsul. 2002, 19 (3), 281-292.

(20) Song, K. C.; Lee, H. S.; Choung, I. Y.; Cho, K. I.; Ahn, Y.; Choi, E. J. The Effect of Type of Organic Phase Solvents on the Particle Size of Poly(d,I-Lactide-Co-Glycolide) Nanoparticles. Colloids Surf. Physicochem. Eng. Asp. 2006, 276 (1-3), 162-167.

(21) Prat, D.; Hayler, J.; Wells, A. A Survey of Solvent Selection Guides. Green Chem 2014, 16 (10), 4546-4551.

(22) Byrne, F. P.; Jin, S.; Paggiola, G.; Petchey, T. H. M.; Clark, J. H.; Farmer, T. J.; Hunt, A. J.; Robert McElroy, C.; Sherwood, J. Tools and Techniques for Solvent Selection: Green Solvent Selection Guides. Sustain. Chem. Process. 2016, 4 (1), 1-24.

(23) Ortiz de Solorzano, I.; Uson, L.; Larrea, A.; Miana, M.; Sebastian, V.; Arruebo, M. Continuous Synthesis of Drug-Loaded Nanoparticles Using Microchannel Emulsification and Numerical Modeling: Effect of Passive Mixing. Int. J. Nanomedicine 2016, 11, 3397-3416.

(24) Piacentini, E.; Dragosavac, M.; Giorno, L. Pharmaceutical Particles Design by Membrane Emulsification: Preparation Methods and Applications in Drug Delivery. Curr. Pharm. Des. 2017, 23 (2), 302-318.

(25) Liu, R.; Huang, S.-S.; Wan, Y.-H.; Ma, G.-H.; Su, Z.-G. Preparation of Insulin-Loaded PLA/PLGA Microcapsules by a Novel Membrane Emulsification Method and Its Release in Vitro. Colloids Surf. B Biointerfaces 2006, 51 (1), 30-38.

(26) Surh, J.; Vladisavljević, G. T.; Mun, S.; McClements, D. J. Preparation and Characterization of Water/Oil and Water/Oil/Water Emulsions Containing Biopolymer-Gelled Water Droplets. J. Agric. Food Chem. 2007, 55 (1), 175-184.

(27) Vladisavljević, G. T.; Kobayashi, I.; Nakajima, M. Production of Uniform Droplets Using Membrane, Microchannel and Microfluidic Emulsification Devices. Microfluid. Nanofluidics 2012, 13 (1), 151-178.

(28) Matos, M.; Gutiérrez, G.; Iglesias, O.; Coca, J.; Pazos, C. Enhancing Encapsulation Efficiency of Food-Grade Double Emulsions Containing Resveratrol or Vitamin B12 by Membrane Emulsification. J. Food Eng. 2015, 166, 212-220.

(29) Drioli, E.; Brunetti, A.; Di Profio, G.; Barbieri, G. Process Intensification Strategies and Membrane Engineering. Green Chem. 2012, 14 (6), 1561.

(30) Roschangar, F.; Sheldon, R. A.; Senanayake, C. H. Overcoming Barriers to Green Chemistry in the Pharmaceutical Industry - the Green Aspiration Level ${ }^{\mathrm{TM}}$ Concept. Green Chem 2015, $17(2), 752-768$.

(31) Vladisavljević, G. T. Structured Microparticles with Tailored Properties Produced by Membrane Emulsification. Adv. Colloid Interface Sci. 2015, 225, 53-87.

(32) Holdich, R. G.; Dragosavac, M. M.; Vladisavljević, G. T.; Piacentini, E. Continuous Membrane Emulsification with Pulsed (Oscillatory) Flow. Ind. Eng. Chem. Res. 2012, 507-515.

(33) Piacentini, E.; Drioli, E.; Giorno, L. Pulsed Back-and-Forward Cross-Flow Batch Membrane Emulsification with High Productivity to Obtain Highly Uniform and Concentrate Emulsions. J. Membr. Sci. 2014, 453, 119-125. 
(34) Imbrogno, A.; Piacentini, E.; Drioli, E.; Giorno, L. Micro and Nano Polycaprolactone Particles Preparation by Pulsed Back-and-Forward Cross-Flow Batch Membrane Emulsification for Parenteral Administration. Int. J. Pharm. 2014, 477 (1-2), 344-350.

(35) Bazzarelli, F.; Piacentini, E.; Giorno, L. Biophenols-Loaded Solid Lipid Particles (SLPs) Development by Membrane Emulsification. J. Membr. Sci. 2017, 541, 587-594.

(36) Piacentini, E.; Poerio, T.; Bazzarelli, F.; Giorno, L. Microencapsulation by Membrane Emulsification of Biophenols Recovered from Olive Mill Wastewaters. Membranes 2016, 6 (2), 25.

(37) Williams, R. A.; Peng, S. J.; Wheeler, D. A.; Morley, N. C.; Taylor, D.; Whalley, M.; Houldsworth, D. W. Controlled Production of Emulsions Using a Crossflow Membrane. Chem. Eng. Res. Des. 1998, 76 (8), 902-910.

(38) Karbstein, H.; Schubert, H. Developments in the Continuous Mechanical Production of Oilin-Water Macro-Emulsions. Chem. Eng. Process. Process Intensif. 1995, 34 (3), 205-211.

(39) McClements, D. J. Food Emulsions: Principles, Practices, and Techniques, 2 nd ed.; CRC series in contemporary food science; CRC Press: Boca Raton, 2005.

(40) Schultz, S.; Wagner, G.; Urban, K.; Ulrich, J. High-Pressure Homogenization as a Process for Emulsion Formation. Chem. Eng. Technol. 2004, 27 (4), 361-368.

(41) Rosca, I. D.; Watari, F.; Uo, M. Microparticle Formation and Its Mechanism in Single and Double Emulsion Solvent Evaporation. J. Controlled Release 2004, 99 (2), 271-280.

(42) Girault, H. H. .; Schiffrin, D. .; Smith, B. D. . The Measurement of Interfacial Tension of Pendant Drops Using a Video Image Profile Digitizer. J. Colloid Interface Sci. 1984, 101 (1), 257-266.

(43) Drelich, J.; Fang, C.; White, C. Measurement of Interfacial Tension in Fluid-Fluid Systems. Encycl. Surf. Colloid Sci. 2002, 3, 3158-3163.

(44) Imbrogno, A.; Dragosavac, M. .; Piacentini, E.; Vladisavljević, G. T.; Holdich, R. G.; Giorno, L. Polycaprolactone Multicore-Matrix Particle for the Simultaneous Encapsulation of Hydrophilic and Hydrophobic Compounds Produced by Membrane Emulsification and Solvent Diffusion Processes. Colloids Surf. B Biointerfaces 2015, 135, 116-125.

(45) Nanoparticles in Translational Science and Medicine; Villaverde, A., Ed.; Progress in molecular biology and translational science; Elsevier, Acad. Press: Amsterdam, 2011.

(46) Lagarce, F.; Garcion, E.; Faisant, N.; Thomas, O.; Kanaujia, P.; Menei, P.; Benoit, J. P. Development and Characterization of Interleukin-18-Loaded Biodegradable Microspheres. Int. J. Pharm. 2006, 314 (2), 179-188.

(47) Verderio, P.; Bonetti, P.; Colombo, M.; Pandolfi, L.; Prosperi, D. Intracellular Drug Release from Curcumin-Loaded PLGA Nanoparticles Induces G2/M Block in Breast Cancer Cells. Biomacromolecules 2013, 14 (3), 672-682.

(48) Español, L.; Larrea, A.; Andreu, V.; Mendoza, G.; Arruebo, M.; Sebastian, V.; Aurora-Prado, M. S.; Kedor-Hackmann, E. R. M.; Santoro, M. I. R. M.; Santamaria, J. Dual Encapsulation of Hydrophobic and Hydrophilic Drugs in PLGA Nanoparticles by a Single-Step Method: Drug Delivery and Cytotoxicity Assays. RSC Adv 2016, 6 (112), 111060-111069.

(49) Mora-Huertas, C. E.; Fessi, H.; Elaissari, A. Influence of Process and Formulation Parameters on the Formation of Submicron Particles by Solvent Displacement and Emulsificationdiffusion Methods. Adv. Colloid Interface Sci. 2011, 163 (2), 90-122.

(50) Gasparini, G.; Kosvintsev, S. R.; Stillwell, M. T.; Holdich, R. G. Preparation and Characterization of PLGA Particles for Subcutaneous Controlled Drug Release by Membrane Emulsification. Colloids Surf. B Biointerfaces 2008, 61 (2), 199-207. 
(51) Ito, F.; Honnami, H.; Kawakami, H.; Kanamura, K.; Makino, K. Preparation and Properties of PLGA Microspheres Containing Hydrophilic Drugs by the SPG (Shirasu Porous Glass) Membrane Emulsification Technique. Colloids Surf. B Biointerfaces 2008, 67 (1), 20-25.

(52) Yu, Y.; Tan, S.; Zhao, S.; Zhuang, X.; Song, Q.; Wang, Y.; Zhou, Q.; Zhang, Z. Antitumor Activity of Docetaxel-Loaded Polymeric Nanoparticles Fabricated by Shirasu Porous Glass Membrane-Emulsification Technique. Int. J. Nanomedicine 2013, 8, 2641-2652.

(53) Ho, T. H.; Tuyen Dao, T. P.; Nguyen, T. A.; Le, D. D.; Dang, M. C. Cross-Flow Membrane Emulsification Technique for Fabrication of Drug-Loaded Particles. Adv. Nat. Sci. Nanosci. Nanotechnol. 2013, 4 (4), 045008.

(54) Schubert, H.; Ax, K. Engineering Food Emulsions En McKenna, BM. Texture Foods Semisolids 2003.

(55) Schubert, H.; Karbstein, H. Mechanical Emulsification. In Developments in Food Engineering; Yano, T., Matsuno, R., Nakamura, K., Eds.; Springer US: Boston, MA, 1994; pp 9-14.

(56) Park, J. S.; Na, K.; Woo, D. G.; Yang, H. N.; Park, K.-H. Determination of Dual Delivery for Stem Cell Differentiation Using Dexamethasone and TGF-B3 in/on Polymeric Microspheres. Biomaterials 2009, 30 (27), 4796-4805.

(57) Goodfriend, A. C.; Welch, T. R.; Nguyen, K. T.; Johnson, R. F.; Sebastian, V.; Reddy, S. V.; Forbess, J.; Nugent, A. Thermally Processed Polymeric Microparticles for Year-Long Delivery of Dexamethasone. Mater. Sci. Eng. C 2016, 58, 595-600.

(58) Kim, D.-H.; Martin, D. C. Sustained Release of Dexamethasone from Hydrophilic Matrices Using PLGA Nanoparticles for Neural Drug Delivery. Biomaterials 2006, 27 (15), 3031-3037.

(59) Guideline, I. H. T. Impurities: Guideline for Residual Solvents Q3C (R5). Curr. Step 2005, 4, 509.

(60) Lancaster, M. Green Chemistry: An Introductory Text, 3rd edition.; Royal Society of Chemistry: Cambridge, UK, 2016. 


\section{TOC/Abstract graphic and Synopsis}

Polymeric particles production with high yield, minimized solvent and energy consumption and reduced waste by membrane emulsification.

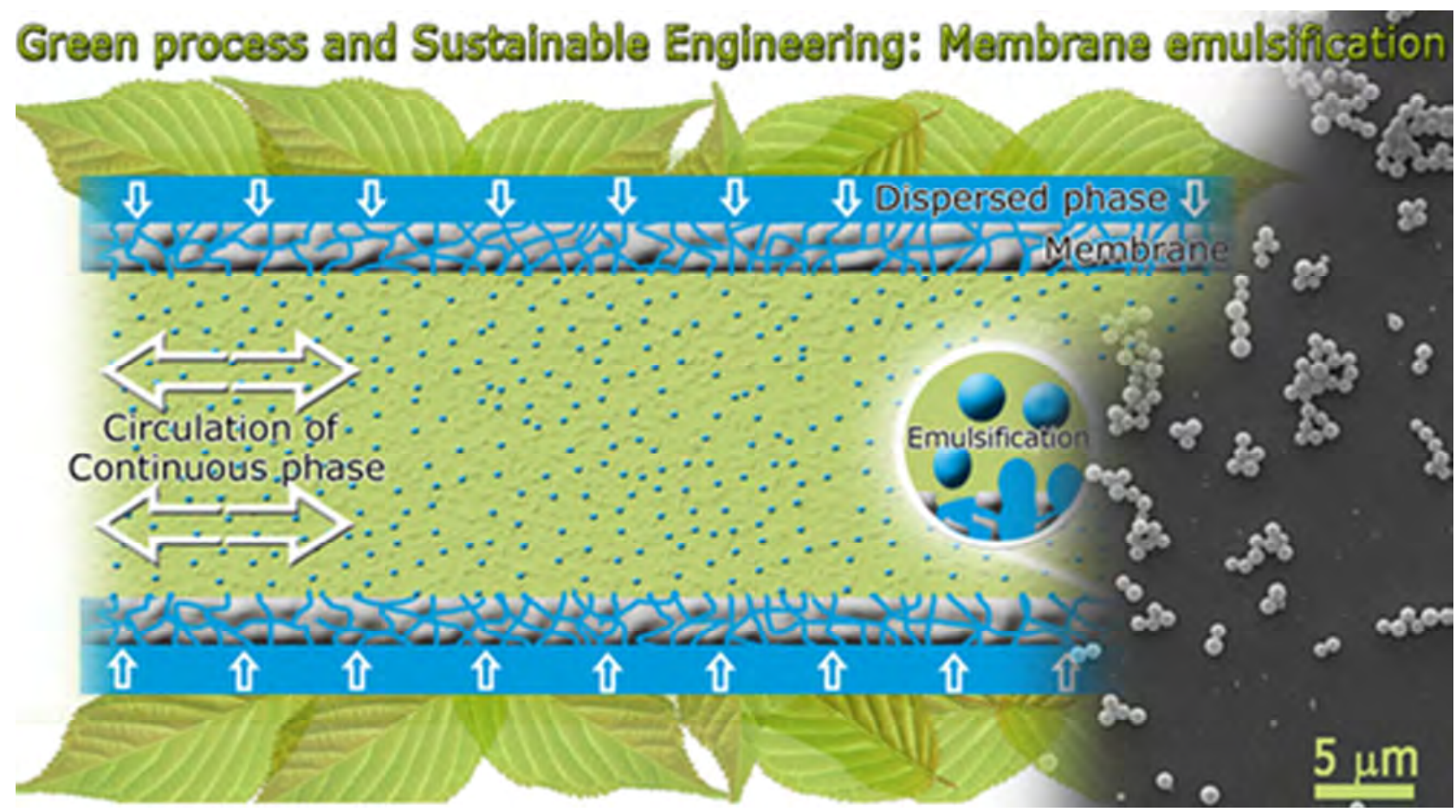

